\title{
Editorial
}

\section{Management of young dyspeptic patients in the community}

There is confusion regarding the optimal strategy for the initial management of patients under the age of 45 years presenting with dyspepsia in the community as there are many different strategies available. If patients present with sinister symptoms such as dysphagia, weight loss or vomiting, or if they are on nonsteroidal anti-inflammatory drugs or they are older, then initial endoscopy is recommended to avoid missing gastric cancer or peptic ulcer. ${ }^{1}$ However, in the majority of young dyspeptic patients who do not have such risk factors, endoscopy is usually normal and the risk of gastric cancer is only about $1-2 \% .^{2}$ To avoid unnecessary endoscopies which can increase waiting lists, various initial noninvasive strategies have been utilised. Empirical treatment with antisecretory therapy had been recommended as the initial treatment by both British and American gastroenterologists. ${ }^{3,4}$ However, the discovery of Helicobacter pylori as a cause of peptic ulcers and the fact that cure of peptic ulcers can be achieved by eradicating $H$ pylori has made the use of noninvasive testing for $H$ pylori to select patients for endoscopy or initial empirical antimicrobial therapy seem attractive. The recent British Society of Gastroenterology guidelines ${ }^{3}$ advise the initial use of $H$ pylori serology in conjunction with empirical antisecretory therapy. If patients remain symptomatic following empirical antisecretory therapy and are $H$ pylori seropositive, then they will proceed to endoscopy for further evaluation. These guidelines are based mainly on British studies and a careful use of limited endoscopic resources. Hence, the guidelines are not necessarily universally applicable, as endoscopic resources differ in different countries. In addition there have been very few prospective studies of the management of dyspepsia to guide us and decision analyses on the various strategies have conflicting findings.

Five initial noninvasive strategies for managing young dyspeptic patients are used in practice:

1 Empirical antisecretory therapy, eg, ranitidine for 4-8 weeks. If patients remain symptomatic or relapse, they undergo endoscopy.

2 Empirical antisecretory therapy and $H$ pylori serology as recommended by the British Society of Gastroenterology.

$3 H$ pylori serology-if patients are found to be seropositive, they undergo endoscopy.

$4 \quad H$ pylori serology - if patients are found to be seropositive, they are given $H$ pylori eradication therapy.

5 Empirical $H$ pylori eradication therapy, ie, treating all dyspeptics with eradication therapy without testing for $H$ pylori.

In strategies (3) and (4), $H$ pylori seronegative patients will be reassured and given symptomatic treatment.

The invasive stategy is to offer initial endoscopy for all dyspeptics. Initial endoscopy has been compared to empirical H2 receptor antagonist therapy in a prospective randomised study in Denmark. ${ }^{5}$ The authors found that after a one-year follow-up, initial endoscopy was more cost

1 Axon AT, Bell GD, Jones RH, Quine MA, McCloy RF. Guidelines on appropriate indications for upper gastrointestinal endoscopy. Working Party of the Joint Committee of the Royal College of Physicians of London, Royal College of Surgeons of England, Royal College of Anaesthetists, Association of Surgeons, the British Society of Gastroenterology, and the Thoracic Society of Great Britain. BMF 1995; 310: 853-6. effective because of a lower number of lost work days and reduced ulcer medication use in this group. The majority of patients who had initial empirical therapy eventually required endoscopy $(70 \%)$. A prospective study in the UK evaluated the use of $H$ pylori serology where seropositive patients had endoscopy while seronegative patients had symptomatic treatment. ${ }^{6}$ After a six-month follow-up, $36 \%$ of endoscopies were avoided. Only three of 70 seronegative patients eventually required endoscopy, which was normal. In the seronegative group there was a significant decrease in symptoms, reduced life-events interference and reduced medication use.

A decision analysis study from the UK compared 10year cumulative costs of empirical antisecretory therapy with cimetidine versus screening for $H$ pylori. ${ }^{7}$. They found that eradication therapy was cheaper than maintenance cimetidine therapy for proven peptic ulcers. However, when the initial cost of identifying the appropriate patients for eradication therapy using $H$ pylori serology was taken into account, then cost savings can take up to eight years to accrue. A US study evaluated the cost per ulcer cured and the cost per patient treated for the strategies of initial endoscopy plus biopsy for $H$ pylori, initial endoscopy without biopsy, initial serology for $H$ pylori, initial empirical antisecretory therapy, and initial empirical antisecretory therapy plus $H$ pylori eradication therapy. ${ }^{8}$ They found that although initial endoscopy was the most expensive strategy, it guided diagnosis and reduced the number of patients inappropriately treated. However, the safety and effectiveness of less expensive and less invasive strategies supported the initial noninvasive care of dyspeptic patients. Another US study evaluated the cost of direct medical care in the first year comparing initial endoscopy with empirical antisecretory therapy with or without $H$ pylori serology. ${ }^{9}$ They found that initial serology for $H$ pylori, followed by endoscopy if seropositive, would be more expensive than initial endoscopy. In contrast, if $H$ pylori seropositive patients received antimicrobial therapy for eradication instead, this would be cheaper than initial endoscopy.

In conclusion, how should young dyspeptic patients be managed initially? If they have sinister symptoms or are taking nonsteroidals, they should be endoscoped. For the remainder, the most effective strategy may depend on local circumstances. If endoscopy resources are unlimited, it may be more cost-effective to proceed to initial endoscopy rather than noninvasive strategies. However, if endoscopic resources are limited, then any of the noninvasive strategies to exclude those in whom initial endoscopy is not required appears to be effective.

TONY CK THAM Department of Medicine, Ulster Hospital, Dundonald, Belfast BT16 ORH, Northern Ireland, UK

2 Williams B, Luckas M, Ellingham JMH, Dain A, Wicks ACB. Do young patients with dyspepsia need investigation? Lancet 1988, ii: 1349-51.

3 British Society of Gastroenterology. Dyspepsia management guidelines. London: 1996. 
4 Anonymous. Endoscopy in the evaluation of dyspepsia. Health and Public Policy Committee, American College of Physicians. Ann Intern Med 1985; 102: $266-9$.

5 Bytzer P, Hansen JM, Schaffalitzky de Muckadell OB. Empirical H2 blocker therapy or prompt endoscopy in management of dyspepsia. Lancet 1994; 343: $811-6$.

6 Patel P, Khulusi S, Mendall MA, Lloyd R, Maxwell JD, Northfield TC Prospective screening of dyspeptic patients by Helicobacter pylori serology. Lancet 1995; 346: $1315-18$.

7 Briggs AH, Sculpher MJ, Logan RPH, Aldous J, Ramsay ME, Baron JH. Cost effectiveness of screening for and eradication of Helicobacter pylori in Cost effectiveness of screening for and eradication of Helicobacter pylori in
management of dyspeptic patients under 45 years of age. BMf 1996; 312: $1321-5$.
8 Fendrick AM, Chernew ME, Hirth RA, Bloom BS. Alternative management strategies for patients with suspected peptic ulcer disease. Ann Intern Med 1995; 123: $260-8$

9 Silverstein MD, Petterson T, Talley NJ. Initial endoscopy or empirical therapy with or without testing for Helicobacter pylori for dyspepsia: a decision analysis. Gastroenterology 1996; 110: 72-83.

\section{Postgraduate Medical Journal-http://www.postgradmedj.com}

Visitors to the WorldWide Web can now access the Postgraduate Medical fournal either through the BMJ Publishing Group's home page (http://www.bmjpg.com) or directly by using its individual URL (http://www.postgradmedj.com). There they will find the following:

- current contents list for the journal

- contents lists of previous issues

- members of the editorial board

- subscribers' information

- instructions for authors

- details of reprint services.

A hotlink gives access to:

- BMJ Publishing Group home page

- British Medical Association website

- On-line books catalogue

- BMJ Publishing Group books

The website is at a preliminary stage and there are plans to develop it into a more sophisticated site. Suggestions from vistors about features they would like to see are welcomed. They can be left via the opening gate of the BMJ Publishing Group site or, alternatively, via the journal page, through 'about this site'. 